\title{
Are patients with multiple sclerosis (MS) at higher risk of COVID-19 infection?
}

\section{Mahsa Ghajarzadeh $^{1}$ (D) $\cdot$ Simona Bonavita ${ }^{2}$}

Received: 3 June 2020 / Accepted: 2 July 2020 / Published online: 7 July 2020

(C) Fondazione Società Italiana di Neurologia 2020

\section{Dear Sir,}

Severe acute respiratory syndrome coronavirus 2 (SARSCoV-2) disease (COVID-19) emerged first in Wuhan city of China and has been declared a pandemic [1]. Patients with underlying diseases such as diabetes, hypertension, and lung diseases are at higher risk of infection [2]. The symptoms include fever, dry cough, shortness of breath, fatigue, and in some cases gastrointestinal manifestations as well as hyposmia/anosmia and hypogeusia/ageusia [3]. Lymphopenia is a common laboratory finding [4]. Severe cases could develop acute respiratory distress syndrome (ARDS) or become fatal [5]. The rapid spread of the disease raises concerns regarding patients with autoimmune diseases receiving immunomodulatory or immunosuppressive agents such as people with (pw) multiple sclerosis (MS). Different factors play a role in COVID-19 morbidity and mortality in pwMS such as age, smoking habit, disability status, overweight due to reduced mobility, respiratory comorbidities, ongoing diseasemodifying therapy (DMT), and the number of medical center visits needed for MRI examination, laboratory exam, clinical visits, or hospitalizations that are relapse related or for medication infusion during pandemic [6]. Considering DMT, first-line treatment includes interferons (IFNs) and glatiramer acetate thatare classified as very low-risk medication for pwMS during COVID-19 pandemic as well as teriflunomide [6]. In particular, INFs are supposed to be effective in treating viral infections as

Mahsa Ghajarzadeh

m.ghajarzadeh@gmail.com

1 Universal Council of Epidemiology (UCE), Universal Scientific Education and Research Network (USERN), Tehran University of Medical Sciences, Tehran, Iran

2 Department of Advanced Medical and Surgical Sciences, University of Campania "Luigi Vanvitelli”, Piazza Miraglia, 2, 80138 Naples, Italy they inhibit replication of the viruses and play a role in developing adaptive immunity [7].

Other medications such as natalizumab and dimethyl fumarate are considered as low risk, while S1P modulator (fingolimod, siponimod, ozanimod, and ponesimod) and cladribine as medications with intermediate risk of infection [6]. Anti-CD20 medications such as rituximab, ocrelizumab, ofatumumab, and ublituximab deplete peripheral B cells which results in decrease of IL-6 production and reduction of inflammatory responses [8]. Of note IL-6 has a critical negative impact in Pneumovirus infection in the mouse [9] and levels of IL-6 are significantly higher in patients with ARDS as compared with patients with only severe pneumonia [10].

Other treatments which are used for irresponsive patients (mitoxantrone, alemtuzumab, and haematopoietic stem cell transplantation) are considered high-risk medications.

Based on the Multiple Sclerosis International Federation (MSIF), should continue their medications and if they develop symptoms or become test positive, consultation is recommended (https://www.msif.org/news/2020/02/10/thecoronavirus-and-ms-what-you-need-to-know/).

On the other hand, vitamin D is an immune modulator which plays an important role in the pathogenesis of many autoimmune diseases. Its deficiency is associated with ARDS, respiratory syncytial virus infection, and influenza and also overproduction of the cytokines [11-13] and prophylactic therapy reduces the risk of respiratory infection [14].

Vitamin D deficiency is considered one of the risk factors in MS, and in most cases, vitamin D is associated with the ongoing DMT to better control the disease course [15]. For pwMS, daily administration of 2000-3000 UI vitamin D supplements is recommended and for cases with vitamin deficiency based on laboratory findings 50,000 IU every 2 weeks for 8 weeks and then following 2000-3000 IU/day [16].

In conclusion, it might be supposed that some pwMS being treated with drugs potentially interfering with viral replication or lowering serum levels of cytokines involved in the development 
of ARDS might be at minor risk of developing severe clinical manifestation from SARS-Cov-2 infection.

\section{Compliance with ethical standards}

Conflict of interest None.

Ethical approval None.

\section{References}

1. WHO. WHO Director-General's opening remarks at the media briefing on COVID-19 - 11 March 2020. March 11 hwwidsd

2. Fang L, Karakiulakis G, Roth M (2020) Are patients with hypertension and diabetes mellitus at increased risk for COVID-19 infection? Lancet Respir Med 8:e21

3. Huang C, Wang Y, Li X, Ren L, Zhao J, Hu Y, Zhang L, Fan G, Xu J, Gu X, Cheng Z, Yu T, Xia J, Wei Y, Wu W, Xie X, Yin W, Li H, Liu M, Xiao Y, Gao H, Guo L, Xie J, Wang G, Jiang R, Gao Z, Jin Q, Wang J, Cao B (2020) Clinical features of patients infected with 2019 novel coronavirus in Wuhan, China. Lancet 395(10223):497-506

4. Favalli EG, Ingegnoli F, De Lucia O, Cincinelli G, Cimaz R, Caporali R (2020) COVID-19 infection and rheumatoid arthritis: faraway, so close! Autoimmun Rev 19(5):102523

5. Yang X, Yu Y, Xu J, Shu H, Liu H, Wu Y et al (2020) Clinical course and outcomes of critically ill patients with SARS-CoV-2 pneumonia in Wuhan, China: a single-centered, retrospective, observational study. Lancet Respir Med 8(5):475-481

6. Giovannoni G, Hawkes C, Lechner-Scott J, Levy M, Waubant E, Gold J (2020) The COVID-19 pandemic and the use of MS diseasemodifying therapies. Mult Scler Relat Disord 39:102073

7. Totura AL, Baric RS (2012) SARS coronavirus pathogenesis: host innate immune responses and viral antagonism of interferon. Curr Opin Virol 2(3):264-275
8. Moreno Torres I, Garcia-Merino A (2017) Anti-CD20 monoclonal antibodies in multiple sclerosis. Expert Rev Neurother 17(4):359-371

9. Chen C, Shi L, Li Y, Wang X, Yang S (2016) Disease-specific dynamic biomarkers selected by integrating inflammatory mediators with clinical informatics in ARDS patients with severe pneumonia. Cell Biol Toxicol 32(3):169-184

10. Percopo CM, Ma M, Brenner TA, Krumholz JO, Break TJ, Laky K, Rosenberg HF (2019) Critical adverse impact of IL-6 in acute pneumovirus infection. J Immunol 202(3):871-882

11. Berry DJ, Hesketh K, Power C, Hyppönen E (2011) Vitamin D status has a linear association with seasonal infections and lung function in British adults. Br J Nutr 106(9):1433-1440

12. Cannell J, Vieth R, Umhau J, Holick M, Grant W, Madronich S et al (2006) Epidemic influenza and vitamin D. Epidemiol Infect 134(6): $1129-1140$

13. Khare D, Godbole NM, Pawar SD, Mohan V, Pandey G, Gupta S, Kumar D, Dhole TN, Godbole MM (2013) Calcitriol [1, 25 [OH] 2 D3] pre-and post-treatment suppresses inflammatory response to influenza A (H1N1) infection in human lung A549 epithelial cells. Eur J Nutr 52(4):1405-1415

14. Bergman P, Lindh ÅU, Björkhem-Bergman L, Lindh JD (2013) Vitamin D and respiratory tract infections: a systematic review and meta-analysis of randomized controlled trials. PLoS One 8(6): 65835

15. Laursen JH, Søndergaard HB, Sørensen PS, Sellebjerg F, Oturai AB (2016) Vitamin D supplementation reduces relapse rate in relapsing-remitting multiple sclerosis patients treated with natalizumab. Mult Scler Relat Disord 10:169-173

16. Faridar A, Eskandari G, Sahraian MA, Minagar A, Azimi A (2012) Vitamin D and multiple sclerosis: a critical review and recommendations on treatment. Acta Neurol Belg 112(4):327-333

Publisher's note Springer Nature remains neutral with regard to jurisdictional claims in published maps and institutional affiliations. 